\title{
Caracterización morfo-agronómica de poblaciones de zapallo criollo (cucurbita maxima Duch.) colectadas en los valles andinos de la Argentina
}

Lorello, I.M.; S.C. García Lampasona, M.A. Makuch e I.E. Peralta

\begin{abstract}
RESUMEN
En los valles andinos de la Argentina las familias producen hortalizas en forma tradicional principalmente para el autoconsumo. El zapallo (Cucurbita maxima) es un cultivo americano de gran importancia en las economías regionales andinas. Estas poblaciones criollas de zapallos se están perdiendo por el éxodo rural, la sustitución de semilla criolla por semilla comercial y las sequías frecuentes. Constituyen reservorios de genes de interés para el mejoramiento y para garantizar la seguridad alimentaria local, por lo que su conservación y caracterización son fundamentales para evitar la erosión genética. Durante 2005 se realizaron colectas en Valle Fértil, provincia de San Juan y en el noroeste argentino; se colectaron 61 poblaciones, de las cuales 27 se seleccionaron y evaluaron durante dos años en la EEA La Consulta INTA, Mendoza. Se midieron 49 caracteres de planta, flor, fruto y semilla, bajo un diseño experimental completamente aleatorizado y tres repeticiones por población. Los cultivares comerciales Marino FCA y Veronés INTA se emplearon como testigos. Las poblaciones se agruparon por caracteres de fruto, hábito de crecimiento y semilla, observándose gran diversidad morfológica entre y dentro de cada población. El trabajo permitió seleccionar materiales con caracteres de interés para el mejoramiento de la especie.
\end{abstract}

Palabras clave: Cucurbita maxima, caracterización morfo-agronómica, diversidad genética, recursos genéticos

Lorello, I.M.; S.C. García Lampasona, M.A. Makuch and I.E. Peralta, 2016. Morpho-agronomic characterization of squash (Cucurbita maxima Duch.) landraces from the andean valleys in Argentina. Agriscientia 33 (1): 47-60

\section{SUMMARY}

In the Andean valleys of Argentina, families grow vegetables by traditional methods, mainly for self-consumption. Squash (Cucurbita maxima) is an 
American crop of great importance in Andean regional economies. These squash landraces are being lost by the rural exodus, the replacement of local varieties with commercial seeds and frequent droughts. They are reservoirs of genes of interest for improving the species and for ensuring local food security; their conservation and characterization are thus fundamental to avoiding genetic erosion. During 2005, sixty-one populations were collected from Valle Fértil, San Juan Province, and from the Argentinian northwest. Twentyseven were selected and tested for two years in the EEA INTA La Consulta, Mendoza. Forty-nine characters of plant, flower, fruit and seed were measured under a completely randomized design with three repetitions per population. Commercial cultivars Marino FCA and Veronés INTA were used as controls. The populations were grouped by fruit, seed and growth habit characters; a great morphological diversity was observed among and within populations. The work allowed selection of materials with desirable traits for improving the species.

Keywords: Cucurbita maxima, morph-agronomic characterization, genetic diversity, genetic resources

I.M. Lorello: Instituto Nacional de Tecnología Agropecuaria (INTA), Estación Experimental Agropecuaria (EEA), La Consulta km 96, ex Ruta 40, La Consulta (5567), CC 8, Mendoza, Argentina. Cátedra de Botánica Agrícola, Universidad Nacional de Cuyo (UNCuyo), Facultad de Ciencias Agrarias (FCA), Almirante Brown 500, Chacras de Coria (M5528AHB), Mendoza, Argentina. S.C. García Lampasona: INTA, EEA Mendoza, San Martín 3853, (5507), Mendoza, Argentina. Laboratorio de Biología Molecular, Instituto de Biología Agrícola de Mendoza, Consejo Nacional de Investigaciones Científicas y Técnicas (IBAM-CONICET), Universidad Nacional de Cuyo (UNCuyo), Facultad de Ciencias Agrarias (FCA), Almirante Brown 500, Chacras de Coria, Mendoza, Argentina. M.A. Makuch: Instituto Nacional de Tecnología Agropecuaria (INTA), Estación Experimental Agropecuaria (EEA) La Consulta. km 96 ex Ruta 40. La Consulta (5567), CC 8. Mendoza, Argentina. I.E. Peralta: Cátedra de Botánica Agrícola, Universidad Nacional de Cuyo (UNCuyo), Facultad de Ciencias Agrarias (FCA), Almirante Brown 500, Chacras de Coria (M5528AHB), Mendoza, Argentina. Instituto Argentino de Investigaciones de Zonas Áridas (IADIZA) Centro Científico Tecnológico (CCT) Consejo Nacional de Investigaciones Científicas y Tecnológicas (CONICET), Mendoza. Correspondencia a: Iorello.ines@inta.gob.ar, ilorello@fca.uncu.edu.ar.

\section{INTRODUCCIÓN}

El zapallo, Cucurbita maxima Duchesne, es un cultivo americano que se desarrolla en zonas andinas y en las más variadas condiciones ambientales. Dentro de su área de distribución nativa existen variantes que se cultivan en un amplio intervalo altitudinal, desde los $100 \mathrm{~m}$ en Brasil hasta los 3000 m en Bolivia (Lira Saade, 1996). En la actualidad se cultiva en todo el mundo, preferentemente en zonas templadas.

Vavílov (1931) postuló que C. maxima fue domesticada en el centro sudamericano de origen de las especies (Perú-Ecuador-Bolivia) junto con otros cultivos como el pimiento (Capsicum annuum L.), el tomate (Solanum lycopersicum L.) y la papa (So- lanum tuberosum L.). El noroeste argentino forma parte de dicho centro de origen en cuyas latitudes se dieron condiciones propicias para el establecimiento de poblaciones humanas, dando lugar al nacimiento de la agricultura sudamericana (LoreIlo, 2012; Lorello et al., 2013).

Las variedades tradicionales o criollas constituyen plantas cultivadas, adaptadas a los lugares y culturas donde se desarrollan. Están presentes en los bancos de semillas de muchos agricultores, principalmente de países en desarrollo, justamente por constituir la garantía de plantación del año siguiente (Domínguez et al., 2000). Los cultivares criollos se encuentran principalmente en zonas de agricultura de subsistencia, donde se producen con métodos tradicionales con el fin de abastecer 
a la familia y mercados locales.

El zapallo en particular, forma parte de la dieta y economía regional de las comunidades andinas desde épocas precolombinas (Peralta et al., 2008). Es un alimento de gran digestibilidad, que aporta nutrientes valiosos como beta carotenos, provitamina A y antioxidantes, cuya conservación es prioritaria para la Argentina (Seroczyńska et al., 2006; Rahman et al., 2008).

Las culturas andinas domesticaron numerosas especies a través de un largo proceso de selección artificial que, junto con la presión natural del ambiente, generó cultivares con importantes diferencias genéticas. Como parte de la valoración y conocimiento de esta enorme diversidad, el trabajo de multiplicación y caracterización cobra gran importancia en la preservación de la variabilidad genética existente en la agricultura tradicional. Por otra parte, la información generada mediante la caracterización resulta de utilidad para el mejorador en la identificación de progenitores con genotipos deseables (Torres Filho et al., 2009) y en la disponibilidad de un reservorio de diversidad alélica. En 1994 el Instituto Nacional de Tecnología Agropecuaria (INTA) consolidó una red de bancos de germoplasma abocados a la conservación de recursos genéticos, de la cual forma parte el Banco de
Germoplasma de especies hortícolas, aromáticas y medicinales ubicado en la Estación Experimental Agropecuaria (EEA), La Consulta, Mendoza. La preocupación mundial por la preservación de los recursos del género Cucurbita se manifiesta en trabajos de caracterización como los de Ferriol et al. (2004), Montes et al. (2004), Bih Achu et al. (2005), Morales et al. (2007), Rahman et al. (2008), Tsivelikas et al. (2009) y Balkaya et al. (2010).

Las especies del género Cucurbita presentan plantas alógamas, de polinización entomófila (Hurd \& Linsley, 1964, 1967, 1970; Hurd et al., 1971), con frutos de tipo pepónide. El género Cucurbita posee 20 pares de cromosomas $(2 n=40)$ (McKay, 1931; Whitaker, 1933; Whitaker \& Davis, 1962) y se considera que es un antiguo tetraploide (Weeden, 1984; Weeden \& Robinson, 1990). C. maxima constituye dentro del género Cucurbita, una de las especies cultivadas más diversas con numerosas variedades locales, cultivares comestibles y ornamentales. El uso más común es el consumo de su pulpa madura, que es una de las de mejor calidad dentro del género por su sabor y riqueza en carotenoides (Itle \& Kabelka, 2009; Della Gaspera \& Rodríguez, 2013).

Las variedades de $C$. maxima utilizadas en América y en Europa pueden agruparse en seis tipos:

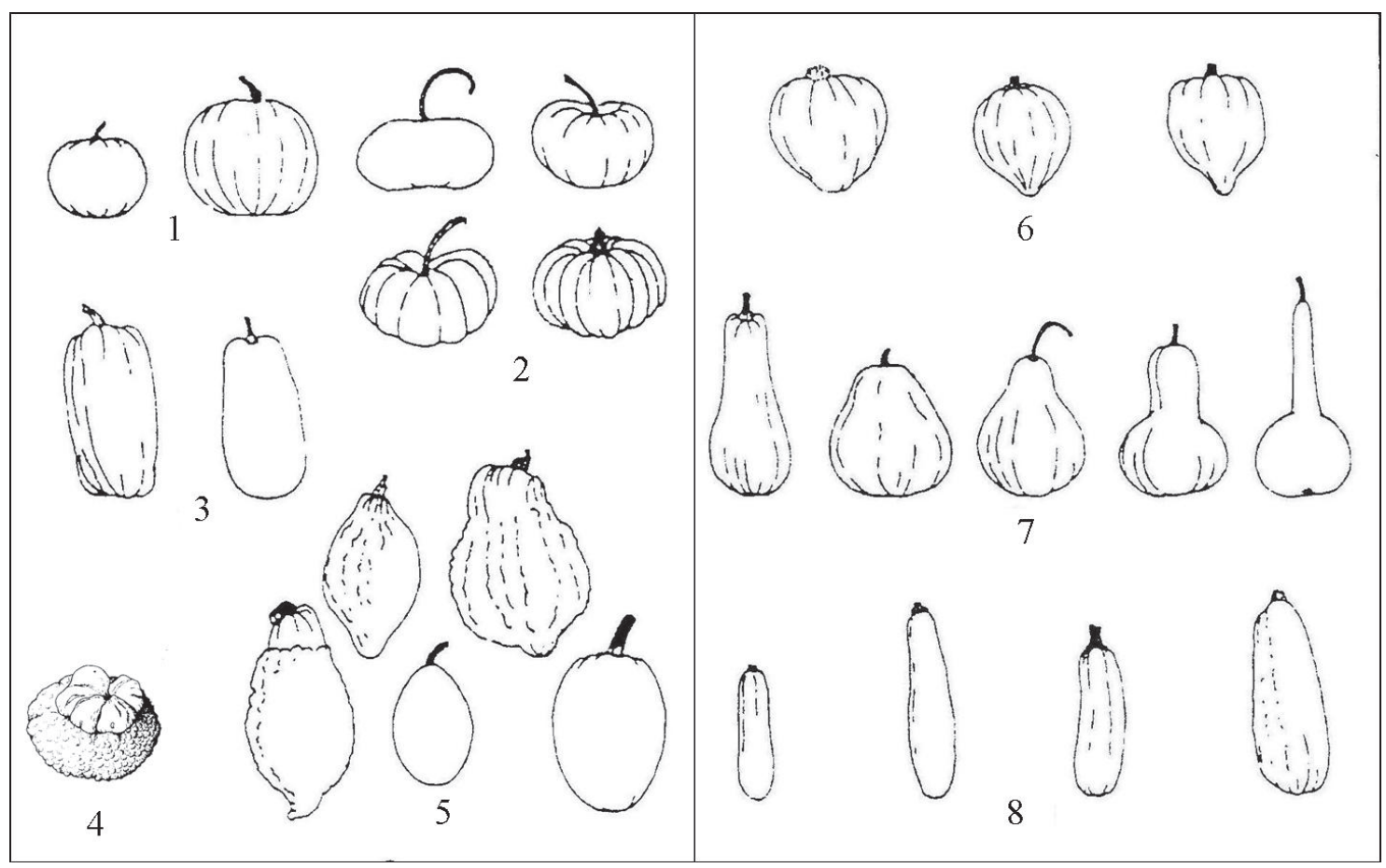

Figura 1. Esquema de las distintas formas de fruto adoptadas por la especie Cucurbita maxima. 1, globular (show). 2, achatado (plomo criollo, criollo crespo). 3, oblongo alargado. 4, turbante o turbaniforme. 5, elíptico u oval (hubbard). 6, acorazonado (delicioso, acorn). 7, piriforme (marrow). 8, elongado (banana). (Guzmán et al., 2001). 
"Banana", "Deliciosos", "Hubbard" o "Inglés", "Marrow", "Show" y "Turbaniformes" (León, 2000). En la Argentina se conocen los cultivares: "Criollo Plomo": con frutos de formas oblongas a globulares con costillas marcadas, entre 6 a $15 \mathrm{~kg}$ de peso, corteza color gris plomizo y pulpa naranja; "Criollo Crespo": de frutos achatados a globulares, corteza color gris plomizo con verrugas, frutos de alrededor de $10 \mathrm{~kg}$, buena conservación en poscosecha; "Zapallo de invierno": abarca a todos los zapallos que se consumen maduros e incluyen formas globosas o globulares (Criollo Plomo), oblongas (Banana), chatas (Show, Criollo Crespo), acorazonadas (Acorn, Deliciosos) elípticas (Hubbard), piriformes (Marrow); "Turbantes": se cultivan como ornamentales; "Zapallito redondo del tronco": (Cucurbita maxima Duchesne var. zapallito) variedad comercial que se consume exclusivamente en la Argentina. Sus plantas forman matas que producen numerosos frutos redondos, chatos que se consumen inmaduros cuando pesan entre 150 y $300 \mathrm{~g}$ (Pedro Della Gaspera 2005, comunicación personal; Astorquizaga, 2009). En la Figura 1 se esquematizan los morfotipos detallados previamente.

En la Argentina C. maxima está escasamente representada en los bancos de germoplasma y no existen trabajos previos de colectas y caracterización sistemáticas de la especie. En este contexto el presente trabajo tuvo como objetivos caracterizar 27 poblaciones de C. maxima colectadas en los valles andinos de Valle Fértil, San Juan y del noroeste argentino (NOA) (Asprelli et al., 2012), de acuerdo a descriptores para el género; evaluar diversidad genética en base a dicha caracterización y multiplicar semilla de las poblaciones evaluadas para abastecer al Banco de Germoplasma de la EEA INTA La Consulta.

\section{MATERIALES Y MÉTODOS}

La caracterización morfo-agronómica se realizó de acuerdo con los descriptores del Instituto Nacional de Semillas para el género Cucurbita spp. (Instituto Nacional de Semillas INASE) y con el Catálogo de Recursos Genéticos Bolivianos de Amaranthus, Capsicum, Cucurbitaceae, Lupinus y Phaseolus (Guzmán et al., 2001) (Tabla 1). Se seleccionaron 27 poblaciones colectadas en Valle Fértil, provincia de San Juan, y la región del noroeste argentino (NOA) (Tabla 2). Para la selección se tuvo en cuenta que cada localidad visitada estuviera representada al menos por una población y que la cantidad de semilla disponible fuera mayor o igual a 100 semillas por población. Como testigos se emplearon los cultivares Marino FCA (tipo comercial zapallo de invier- no o zapallo gris plomo) y el cultivar Veronés INTA (tipo comercial zapallito del tronco). Se evaluaron 15 plantas por población, en tres parcelas totalmente aleatorizadas de cinco plantas cada una, durante dos campañas consecutivas (años 2005-2007). El ensayo tuvo lugar en el campo experimental de INTA La Consulta, Mendoza.

Para las mediciones de color se utilizó un colorímetro Konica Minolta CR-40, considerando el espacio de color de la Commission Internationale de I'Éclairage (CIE L*, $\left.a^{*}, b^{*}\right)$. Las coordenadas $a^{*}$ y b* fueron transformadas para obtener los valores de tono (Hue) y de pureza, saturación o intensidad del color (Chroma), elementos del color perceptibles por el ojo humano junto con L* (McGuire, 1992).

Las mediciones de longitud se realizaron con calibre electrónico, regla graduada y cinta métrica. Se registraron fotografías de cada población mediante una cámara digital.

Con el objetivo de preservar cada población con sus características genéticas originales, se tuvo en cuenta el manejo que los productores hacen del cultivo para la multiplicación de semilla. De esta forma se polinizó de manera manual dentro de cada población y parcela realizando un pool de polen de por lo menos cuatro flores masculinas provenientes de cuatro plantas diferentes de la misma parcela por cada flor femenina polinizada.

\section{Análisis de datos}

Los datos se evaluaron por métodos estadísticos uni y multivariados empleando el programa InfoStat versión 2009 (Balzarini et al., 2008; Di Rienzo et al., 2009). Se realizó un análisis de la varianza (ANAVA) con las variables cuantitativas; se compararon las medias poblacionales para cada variable y se estableció si hubo interacción genotipo ambiente. Se discriminaron las variables cuya variación a lo largo de las mediciones permitió diferenciar poblaciones utilizando la prueba de diferencias mínimas significativas de Fisher, nivel de significancia del $5 \%(\alpha=0,05)$.

Las variables que discriminaron poblaciones en el ANAVA se utilizaron para realizar un análisis de componentes principales (ACP). El análisis se realizó por separado para ambas campañas y en conjunto. Del análisis en conjunto se seleccionaron las variables que más aportaron a las varianzas de cada eje o componente principal, es decir aquellas cuyo coeficiente de correlación fue superior a 0,6 (Matus et al., 1996). A partir de los dos primeros componentes se obtuvo un gráfico de dispersión donde se pudo evaluar el ordenamiento de las poblaciones en un plano bidimensional y establecer 
Tabla 1. Descriptores empleados para la caracterización morfo-agronómica. Número, descripción y estados de los caracteres medidos. Con un asterisco a la derecha se destacan los caracteres cualitativos.

\begin{tabular}{|c|c|c|}
\hline $\mathrm{N}^{\circ}$ & Carácter & Estados asumidos por el carácter \\
\hline 1 & longitud de cotiledón & $\mathrm{mm}$ \\
\hline 2 & ancho de cotiledón & $\mathrm{mm}$ \\
\hline 3 & vigor de la planta * & 1-alto 2-medio 3-bajo \\
\hline 4 & hábito de la planta * & 1-mata 2-mata expandida 3-guías \\
\hline 5 & color de la planta * & 1-verde claro 2-verde mediano 3-verde oscuro \\
\hline 6 & diámetro del entrenudo & $\mathrm{mm}$ \\
\hline 7 & longitud de guía & $\mathrm{m}$ \\
\hline 8 & número de guías & $n^{\circ}$ \\
\hline 9 & presencia de zarcillos * & 1-presente 2-ausente \\
\hline 10 & ancho de hoja & $\mathrm{cm}$ \\
\hline 11 & largo de hoja & $\mathrm{cm}$ \\
\hline 12 & color de hoja * & 1-verde claro 2-verde grisáceo 3-verde medio 4-verde oscuro \\
\hline 13 & color de la hoja * & 1-uniforme 2-manchado \\
\hline 14 & longitud pedicelo de la hoja & $\mathrm{cm}$ \\
\hline 15 & diámetro corola femenina abierta & $\mathrm{cm}$ \\
\hline 16 & longitud pedicelo flor femenina & $\mathrm{cm}$ \\
\hline 17 & forma del ovario * & 1-globoso 2-espiralado 3-fusiforme \\
\hline 18 & días a primera flor femenina & días desde la siembra hasta la apertura de la primer flor femenina \\
\hline 19 & longitud pedicelo flor masculina & $\mathrm{cm}$ \\
\hline 20 & longitud del fruto & $\mathrm{mm}$ \\
\hline 21 & extremo distal del fruto & $\mathrm{mm}$ \\
\hline 22 & extremo proximal del fruto & $\mathrm{mm}$ \\
\hline 23 & peso del fruto & g \\
\hline 24 & forma del fruto * & $\begin{array}{c}\text { 1-chato 2-oblongo 3-oval o elíptico (hubbard) 4-acorazonado (acorn) } \\
\text { 5-piriforme (butternut) 6-turbante 7-redondo del tronco }\end{array}$ \\
\hline 25 & ápice del fruto * & 1-deprimido 2-achatado 3-redondeado 4-agudo \\
\hline 26 & base del fruto * & 1-deprimido 2-achatado 3-redondeado 4-agudo \\
\hline 27 & superficie * & 1-lisa 2-ligeramente rugosa 3-ondeada \\
\hline 28 & cicatriz del botón floral * & 1-deprimida 2-ligeramente extendida 3-elevada \\
\hline 29 & espesor de la corteza media & $\mathrm{mm}$ \\
\hline 30 & consistencia de la corteza * & 1-blanda 2-medianamente dura 3-dura \\
\hline 31 & espesor pulpa extremo distal & $\mathrm{mm}$ \\
\hline 32 & espesor pulpa extremo proximal & $\mathrm{mm}$ \\
\hline 33 & espesor pulpa en la parte media & $\mathrm{mm}$ \\
\hline 34 & color de la pulpa * & 1-verde claro 2-anaranjado claro 3-anaranjado mediano 4-anaranjado intenso \\
\hline 35 & longitud de la cavidad placentaria & $\mathrm{mm}$ \\
\hline 36 & ancho de la cavidad placentaria & $\mathrm{mm}$ \\
\hline 37 & longitud del pedúnculo del fruto & $\mathrm{mm}$ \\
\hline 38 & diámetro del pedúnculo del fruto & $\mathrm{mm}$ \\
\hline 39 & color de corteza & $\mathrm{L}^{*} \mathrm{a}^{*} \mathrm{~b}^{*}$ (brillo, saturación, tono) \\
\hline 40 & color de la pulpa & $\mathrm{L}^{*} \mathrm{a}^{*} \mathrm{~b}^{*}$ (brillo, saturación, tono) \\
\hline 41 & número de frutos por plata & $n^{\circ}$ \\
\hline 42 & longitud de semilla & $\mathrm{mm}$ \\
\hline 43 & ancho de semilla & $\mathrm{mm}$ \\
\hline 44 & superficie de la semilla * & 1-lisa 2-rugosa 3-depresiones 4-pliegues \\
\hline 45 & color de la semilla * & 1-blanco 2-crema 3-tostado 4-castaño \\
\hline 46 & lustre de la semilla * & 1-brillante 2-opaco \\
\hline 47 & color del margen de la semilla * & 1-blanco 2-crema 3- amarillo 4-dorado \\
\hline 48 & peso de 100 semillas & g \\
\hline 49 & rendimiento en semilla & g \\
\hline
\end{tabular}


Tabla 2. Poblaciones evaluadas morfo-agronómicamente. Entr.: número de entrada asignado en las colectas y evaluaciones; Pasap.: pasaporte de entrada en el Banco de Germoplasma EEA La Consulta INTA; Alt.: altitud del punto de colecta; Lat. S-Long. O: coordenadas geográficas del punto de colecta; ubicación geográfica.

\begin{tabular}{|c|c|c|c|c|}
\hline Entr. & Pasap. & Alt. & Lat. S-Long. O & Localidad-Departamento-Provincia \\
\hline$\overline{13}$ & 687 & 961 & $30^{\circ} 29,8--^{\prime} 67^{\circ} 34,5^{\prime}$ & Puesto San Marcos, San Agustín del Valle Fértil, San Juan \\
\hline 14 & 688 & 929 & $30^{\circ} 31,7-67^{\circ} 33,7^{\prime}$ & Usno, San Agustín Del Valle Fértil, San Juan \\
\hline 17 & 678 & 1133 & $30^{\circ} 19,9^{\prime}-67^{\circ} 39,2^{\prime}$ & Baldes Del Rosario, San Agustín del Valle Fértil, San Juan \\
\hline 19 & 694 & 653 & $30^{\circ} 55,5^{\prime}-67^{\circ} 15,3^{\prime}$ & Baldes Del Rosario, San Agustín del Valle Fértil, San Juan \\
\hline 20 & 696 & 1249 & $30^{\circ} 13,2^{\prime}-67^{\circ} 41,7^{\prime}$ & Baldecitos, San Agustín del Valle Fértil, San Juan \\
\hline 22 & 697 & 906 & $30^{\circ} 33,9^{\prime}-67^{\circ} 32,2^{\prime}$ & Usno, San Agustín del Valle Fértil, San Juan \\
\hline 24 & 699 & 722 & $30^{\circ} 47,8^{\prime}-67^{\circ} 19,6^{\prime}$ & Agua Cercada, Valle Fértil-San Juan \\
\hline 36 & 681 & 640 & $30^{\circ} 55,7^{\prime}-67^{\circ} 15,5^{\prime}$ & Baldes De Astica, San Agustín del Valle Fértil, San Juan \\
\hline 53 & 348 & 1208 & $27^{\circ} 56,4^{\prime}-65^{\circ} 41,8^{\prime}$ & La Higuera, Balcosna, Catamarca \\
\hline 62 & 361 & 1274 & $27^{\circ} 51,7^{\prime}-65^{\circ} 45,8^{\prime}$ & Balcosna de Afuera, Catamarca \\
\hline 76 & 620 & 1906 & $26^{\circ} 43,8^{\prime}-66^{\circ} 03,1^{\prime}$ & Loro Huasi, Santa María, Catamarca \\
\hline 127 & 309 & 1215 & $27^{\circ} 43,08^{\prime}-67^{\circ} 08,2^{\prime}$ & Londres, Catamarca \\
\hline 143 & 387 & 1246 & $27^{\circ} 39,1^{\prime}-67^{\circ} 1,3^{\prime}$ & Artasa, Belén, Catamarca \\
\hline 161 & 673 & 1263 & $27^{\circ} 37,8^{\prime}-67^{\circ} 01,5^{\prime}$ & Belén, Catamarca \\
\hline 173 & 2482 & 2083 & $27^{\circ} 09,2^{\prime}-66^{\circ} 42,3^{\prime}$ & Los Nacimientos, Catamarca \\
\hline 185 & 676 & 2131 & $26^{\circ} 21,4^{\prime}-66^{\circ} 01,5^{\prime}$ & Pichao, Tucumán \\
\hline 195 & 418 & 1951 & $25^{\circ} 59,6^{\prime}-66^{\circ} 1,6^{\prime}$ & San Antonio, Cafayate, Salta \\
\hline 210 & 424 & 2004 & $25^{\circ} 59,7^{\prime}-66^{\circ} 01,6^{\prime}$ & San Antonio, Cafayate, Salta \\
\hline 215 & 425 & 1999 & $25^{\circ} 59,6^{\prime}-66^{\circ} 1,4^{\prime}$ & San Antonio, Cafayate, Salta \\
\hline 225 & 428 & 1811 & $26^{\circ} 05,9^{\prime}-66^{\circ} 00,9^{\prime}$ & Divisadero, Salta \\
\hline 233 & 430 & 2432 & $25^{\circ} 22,5^{\prime}-66^{\circ} 26,1^{\prime}$ & Refugios, Luracatao, Salta \\
\hline 244 & 431 & 2400 & $25^{\circ} 22,1^{\prime}-66^{\circ} 25,9^{\prime}$ & Refugios, Luracatao, Salta \\
\hline 284 & 434 & 1663 & $24^{\circ} 02,02^{\prime}-65^{\circ} 26,01^{\prime}$ & Cabrerías, Luracatao, Salta \\
\hline 324 & 440 & 2293 & $23^{\circ} 41,4^{\prime}-65^{\circ} 27,01^{\prime}$ & Chañarcito, Jujuy \\
\hline 367 & 441 & 2370 & $23^{\circ} 39,2^{\prime}-65^{\circ} 25,8^{\prime}$ & Hornillos, Jujuy \\
\hline 382 & 443 & 2761 & $23^{\circ} 30,8^{\prime}-65^{\circ} 24,6^{\prime}$ & Juella, Tilcara, Jujuy \\
\hline 523 & 445 & 3169 & $23^{\circ} 5,3^{\prime}-65^{\circ} 22,9^{\prime}$ & Hornaditas, Humahuaca, Jujuy \\
\hline
\end{tabular}

relaciones entre ellas. También se obtuvo un gráfico de las variables y las poblaciones en un mismo espacio lo que permitió visualizar las asociaciones.

Con el objetivo de establecer relaciones de similitud entre poblaciones en función de sus características categóricas, y discriminar aquellas variables con mayor aporte a la variabilidad observada, se realizó un análisis de correspondencias múltiples (AC).

Utilizando las variables cuantitativas y cualitativas en conjunto, se realizó un análisis de conglomerados con el fin de agrupar las poblaciones en función de sus características comunes, bajo el criterio de máxima similitud entre componentes del grupo y máxima distancia entre grupos. Se utilizaron las variables que mayor aporte hicieron a la variabilidad total observada: las variables cuantitativas informativas previamente seleccionadas por el método de ACP, más las variables cualitativas seleccionadas por AC. La reducción de variables se llevó a cabo con el objetivo de facilitar la interpretación de los grupos obtenidos. Se seleccionó el método de Ward con distancias de Gower
(Gower, 1985), por ser el que mejor describía el agrupamiento de los datos, y manifestar el mayor valor de coeficiente cofenético $(0,8)$. Con base en el conocimiento del material evaluado se estableció el punto de corte en el valor de distancia 0,74 que representa aproximadamente un tercio de la distancia máxima. Cada grupo obtenido se caracterizó a partir de medidas resumen (promedio, desvío estándar, valores mínimo y máximo asumidos por la variable) de los caracteres cuantitativos de mayor relevancia agronómica. Finalmente se realizó un ANAVA para comparar las medias entre los grupos a fin de discriminar las variables que más influyeron en el agrupamiento.

\section{RESULTADOS Y DISCUSIÓN}

\section{Análisis de la varianza (ANAVA)}

Todas las variables consideradas manifestaron diferencias significativas entre poblaciones y se ob- 
Tabla 3. Variables cuantitativas informativas capaces de diferenciar poblaciones, identificadas por medio del análisis de la varianza.

\begin{tabular}{lcc}
\hline$N^{\circ}$ & Variable & Abreviatura \\
\hline 1 & longitud de guía & lon guía \\
2 & ancho de hoja & an hj \\
3 & largo de hoja & lar hj \\
4 & días a primer flor femenina & di pri fem \\
5 & longitud de fruto & lon fr \\
6 & longitud proximal del fruto & prox fr \\
7 & longitud distal del fruto & dist fr \\
8 & espesor de la corteza & esp ct \\
9 & peso del fruto & pes fr \\
10 & longitud de la pulpa distal & ppa dist \\
11 & longitud de la pulpa proximal & ppa prox \\
12 & longitud de la pulpa media & ppa med \\
13 & ancho de la placenta & an plac \\
14 & brillo de la corteza & $\mathrm{L}^{*} \mathrm{Ct}$ \\
15 & saturación o pureza de la corteza & sat ct \\
16 & tono de la corteza & tono ct \\
17 & brillo de la pulpa & $\mathrm{L}^{*} \mathrm{ppa}$ \\
18 & saturación o pureza de la pulpa & sat ppa \\
19 & tono de la pulpa & tono ppa \\
20 & frutos por planta & $\mathrm{fr}$ pl \\
21 & longitud de la semilla & lon se \\
22 & ancho de la semilla & an se \\
\hline
\end{tabular}

servó interacción genotipo-ambiente en la mayoría de los casos. Las variables diámetro de entrenudo y corola de la flor femenina, longitud de guía, longitud de pedicelo de la flor femenina, longitud de fruto y placenta, espesor de corteza, longitud y ancho de semilla manifestaron una moderada o alta heredabilidad ya que su expresión no fue afectada ante cambios ambientales de una campaña a otra de cultivo. Los caracteres más variables, y que permitieron discriminar poblaciones en al menos dos grupos, se seleccionaron como variables informativas (Tabla 3), lo que redujo el número de caracteres cuantitativos de 31 a 22. La mayoría de los caracteres evaluados manifestaron diferencias significativas entre repeticiones, poniendo en evidencia la gran variabilidad dentro de las poblaciones. Esta diversidad intra-poblacional se ve favorecida por el manejo que hacen los productores de sus huertas, quienes seleccionan cada año los frutos de mejor sabor, sanidad y conservación en poscosecha, extraen la semilla y la guardan conjuntamente. Al año siguiente siembran al voleo la mezcla de semillas cosechadas, favoreciendo así la polinización cruzada.

\section{Análisis de componentes principales (ACP)}

El ACP explicó el $80 \%$ de la variabilidad ob- servada en los tres primeros componentes. De las 22 variables seleccionadas con el ANAVA se descartaron las variables longitud de la semilla e intensidad de color de la corteza por no aportar significativamente a la variabilidad observada. Al primer componente aportaron las variables longitud de guía, frutos por planta, días a la aparición de la primera flor femenina, brillo de la corteza, tamaño y peso del fruto, ancho de la placenta, grosor, brillo, saturación y tono de la pulpa. Al segundo componente aportaron las variables ancho de semilla, ancho y largo de hoja, tono de la corteza. El gráfico de dispersión de las poblaciones permitió distinguir tres grupos, de los que quedó excluido el testigo comercial Marino FCA (Figura 2).

El grupo 1 se diferenció significativamente del grupo 2 en las variables número de guías, frutos por planta, tono de la corteza y brillo de la pulpa. Con respecto al grupo 3, el grupo 1 se diferenció significativamente en todas las variables medidas. El grupo 2 se diferenció significativamente del grupo 3 en las variables longitud de guía, longitud y ancho del fruto, espesor de la corteza, peso del fruto, grosor de la pulpa y ancho de la placenta. Estos datos permiten inferir que las poblaciones del grupo 2 son más cercanas morfológicamente a las del grupo 1.

\section{Análisis de correspondencias (AC)}

En el AC las tres primeras dimensiones concentraron el $64 \%$ de la variabilidad observada. Todas las variables fueron bien representadas en las tres dimensiones, excepto el carácter "manchado de la hoja". Un gráfico en ejes cartesianos relacionando las dos primeras dimensiones agrupó las poblaciones en tres conjuntos, definidos por la forma del fruto y ovario, hábito de crecimiento, color de pulpa y semilla. El primer grupo incluyó los zapallitos del tronco. El segundo, poblaciones muy variables con morfotipos de la variedad zapallito del tronco, zapallos tipo turbante y zapallos de invierno. El tercer grupo abarcó el grueso de las poblaciones, con frutos de formas muy variadas: acorazonados, chatos globosos, piriformes, oblongos y ovales (Figura 3). El testigo Marino FCA quedó incluido en el grupo 3. La distribución de las poblaciones a partir del AC coincidió con la del ACP, y permitió discriminar las variables cualitativas más informativas al momento de diferenciar poblaciones, es decir las variables categóricas con mayor aporte a la variabilidad observada. El hecho de reducir el número de variables facilitará el trabajo a campo en futuras mediciones y la interpretación de los resultados. El AC también permitió inferir acerca de las relacio- 


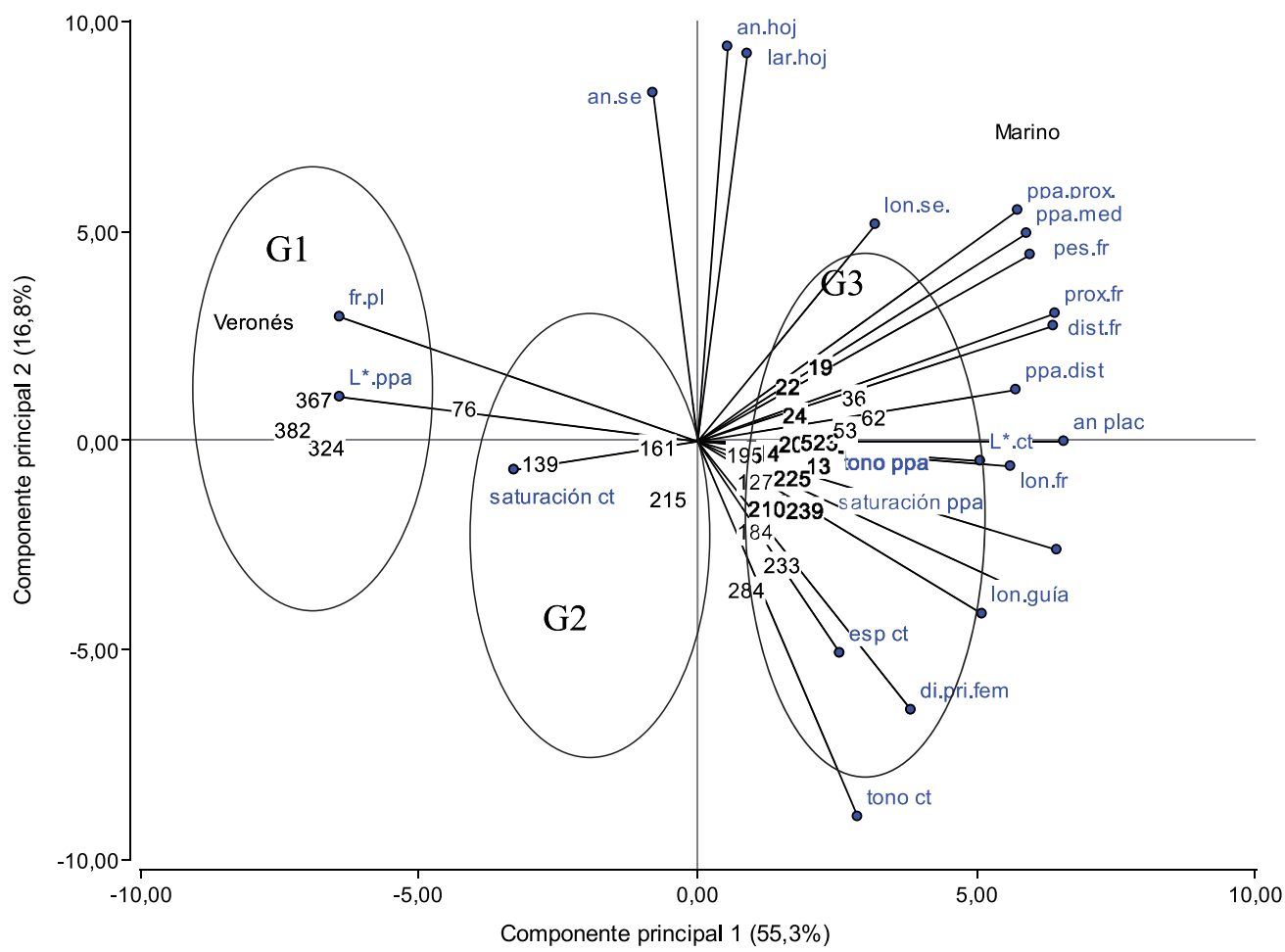

Figura 2. Análisis de componentes principales de 27 poblaciones de Cucurbita maxima y dos testigos: Marino FCA y Veronés INTA. Los números en negro indican las poblaciones; las variables cuantitativas (Tabla 3) se destacan en azul; se identifican con círculos los tres grupos conformados.

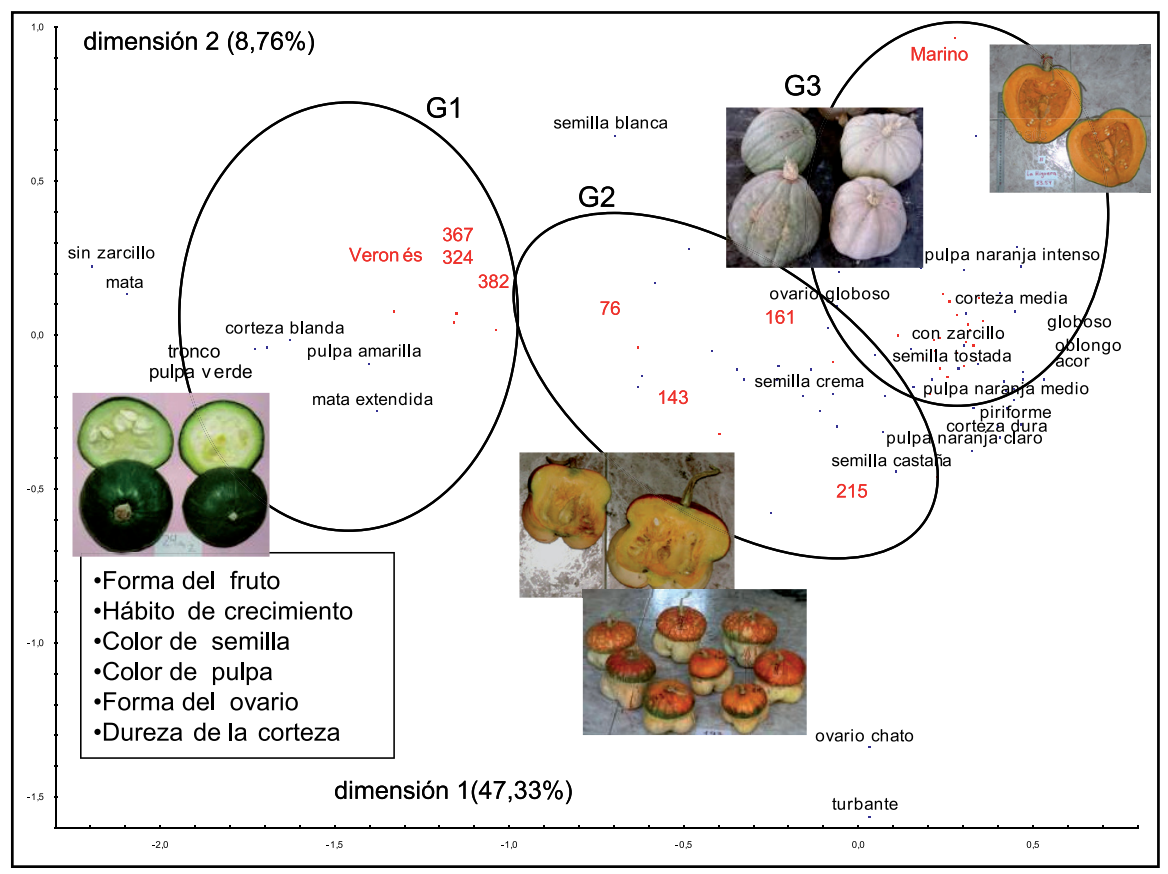

Figura 3. Gráfico de dispersión de 27 poblaciones de C. maxima y dos testigos: Marino FCA y Veronés INTA, a lo largo de las dos primeras dimensiones del AC. En rojo se destacan las poblaciones; en azul las variables y en negro las variables de mayor aporte a la variabilidad observada. 
nes de similitud entre las poblaciones estudiadas en función de las variables categóricas.

\section{Análisis de conglomerados}

Por medio del análisis de conglomerados se conformaron cuatro grupos (Figura 4) cuyas medidas resumen de los caracteres cuantitativos con mayor relevancia agronómica se detallan en la Tabla 4. A continuación se describe cada grupo en función de sus características.

Grupo 1: incluye poblaciones con frutos pequeños de la variedad "zapallito del tronco"; plantas con hábito de crecimiento en mata, sin zarcillos y una sola guía cuya longitud no supera el metro. Presenta flores con ovarios globosos y semillas co-

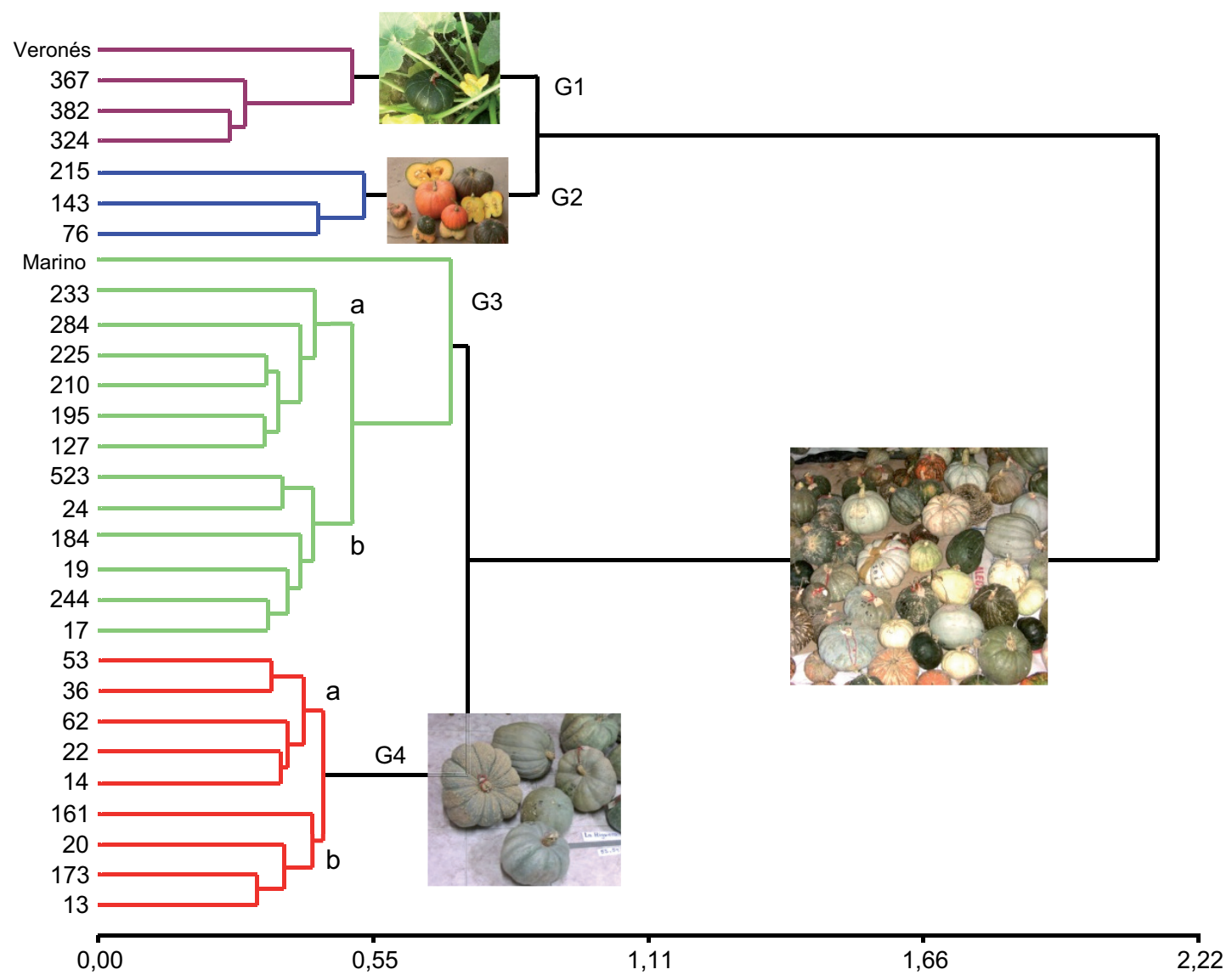

Figura 4. Análisis de conglomerados. Agrupamiento por similitudes de 27 poblaciones de C.maxima y dos testigos: Marino FCA y Veronés INTA, utilizando el algoritmo de Ward y distancias de Gower. Los grupos se diferencian por colores.

Tabla 4. Media y desvío estándar de los caracteres cuantitativos de relevancia agronómica para cada uno de los grupos obtenidos a partir del análisis de conglomerados.

\begin{tabular}{|c|c|c|c|c|c|c|}
\hline Variable & G1 & G 2 & G 3.a & G 3.b & G 4.a & G 4.b \\
\hline longitud guía (m) & $0,7 \pm 0,3$ & $3,0 \pm 0,9$ & $5,5 \pm 1,5$ & $4,0 \pm 0,6$ & $4,2 \pm 0,7$ & $3,7 \pm 0,2$ \\
\hline número guías & $1,1 \pm 0,3$ & $3,2 \pm 0,9$ & $2,9 \pm 0,4$ & $2,9 \pm 0,5$ & $3,1 \pm 0,3$ & $2,9 \pm 0,2$ \\
\hline días primer flor femenina & $57,2 \pm 3$ & $63,2 \pm 10$ & $76,1 \pm 8$ & $72,1 \pm 7$ & $66,3 \pm 5$ & $66,6 \pm 4$ \\
\hline peso fruto (g) & $182,5 \pm 27$ & $1334,1 \pm 88$ & $2122,8 \pm 334$ & $2813,5 \pm 504$ & $3693,6 \pm 786$ & $3058,2 \pm 192$ \\
\hline espesor de pulpa (mm) & $9,6 \pm 2$ & $22,3 \pm 4$ & $26,7 \pm 3$ & $28,0 \pm 2,5$ & $33,9 \pm 4$ & $29,7 \pm 3$ \\
\hline frutos por planta & $9,1 \pm 3$ & $3,9 \pm 2$ & $1,3 \pm 0,2$ & $1,6 \pm 0,4$ & $1,4 \pm 0,3$ & $1,6 \pm 0,8$ \\
\hline semillas por fruto & $99,3 \pm 53$ & $149,2 \pm 30$ & $316,1 \pm 61$ & $301,4 \pm 94$ & $352,5 \pm 41$ & $320,1 \pm 28$ \\
\hline
\end{tabular}


lor blanco y crema. Estas poblaciones resultaron ser las más precoces con una media de 57 días a primera flor femenina, diferenciándose significativamente del grupo 4 con un ciclo 15 días más largo. El rendimiento promedio por planta fue de nueve frutos y menos de $100 \mathrm{~g}$ de semillas por fruto. Este grupo incluye al testigo comercial Veronés INTA (Figura 5).

Grupo 2: abarca poblaciones con frutos de gran diversidad de formas: globosos, chatos y turbaniformes. Algunas poblaciones de este grupo pertenecen a la variedad comercial zapallito redondo del tronco. El $70 \%$ de sus plantas son guiadoras, mientras que el $30 \%$ forma matas o bien matas extendidas. Presentan ovarios globosos y en menor medida chatos. Pulpas en su mayoría de color anaranjado medio a pálido. Semillas color crema, blanco y castaño. Ciclo vegetativo intermedio con 63 días a primera flor femenina. El rendimiento promedio fue de 4 frutos por planta y $150 \mathrm{~g}$ de semilla por fruto (Figura 6).

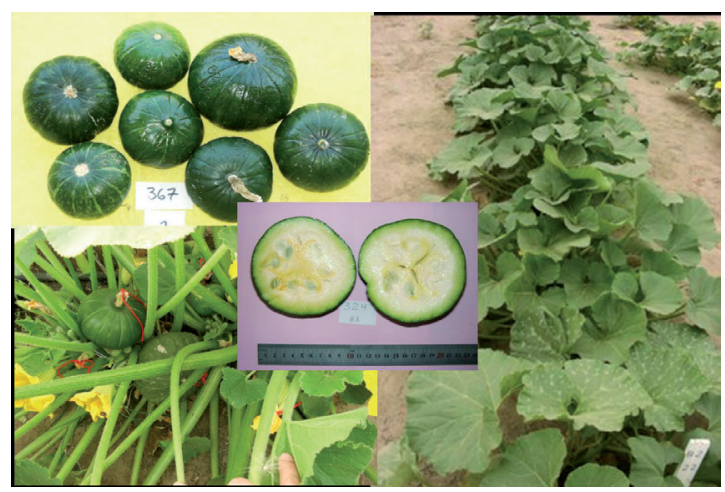

Figura 5. Frutos del grupo 1 según el análisis de conglomerados.
Grupo 3: frutos de formas diversas predominando los globosos y chatos. Sus plantas desarrollan guías con zarcillos, ovarios globosos y fusiformes; pulpas de color anaranjado intenso a medio; semillas de distintos colores que van del crema pasando por el blanco, castaño y tostado. Incluye este grupo las poblaciones con los ciclos de cultivo más largos, alcanzando una media de 73 días a primera flor femenina. Producen uno a dos frutos por planta y un promedio de $300 \mathrm{~g}$ de semilla por fruto. Constituye el segundo grupo con frutos de mayor tamaño y peso después del grupo 4 e incluye al testigo comercial Marino FCA. Dentro del grupo 3 el subgrupo "a" presenta frutos globosos, más pequeños, de alrededor de $2 \mathrm{~kg}$, semillas color crema, más pequeñas y livianas que las del subgrupo 3 "b", y ciclos largos con 76 días a primera flor femenina (Figura 7). El subgrupo "b" desarrolla frutos globosos y chatos, con pesos promedio que

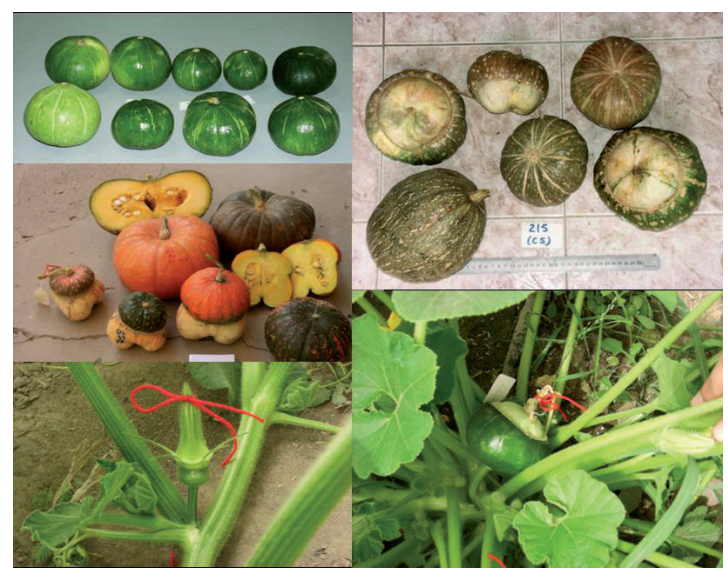

Figura 6. Frutos del grupo 2 según el análisis de conglomerados.

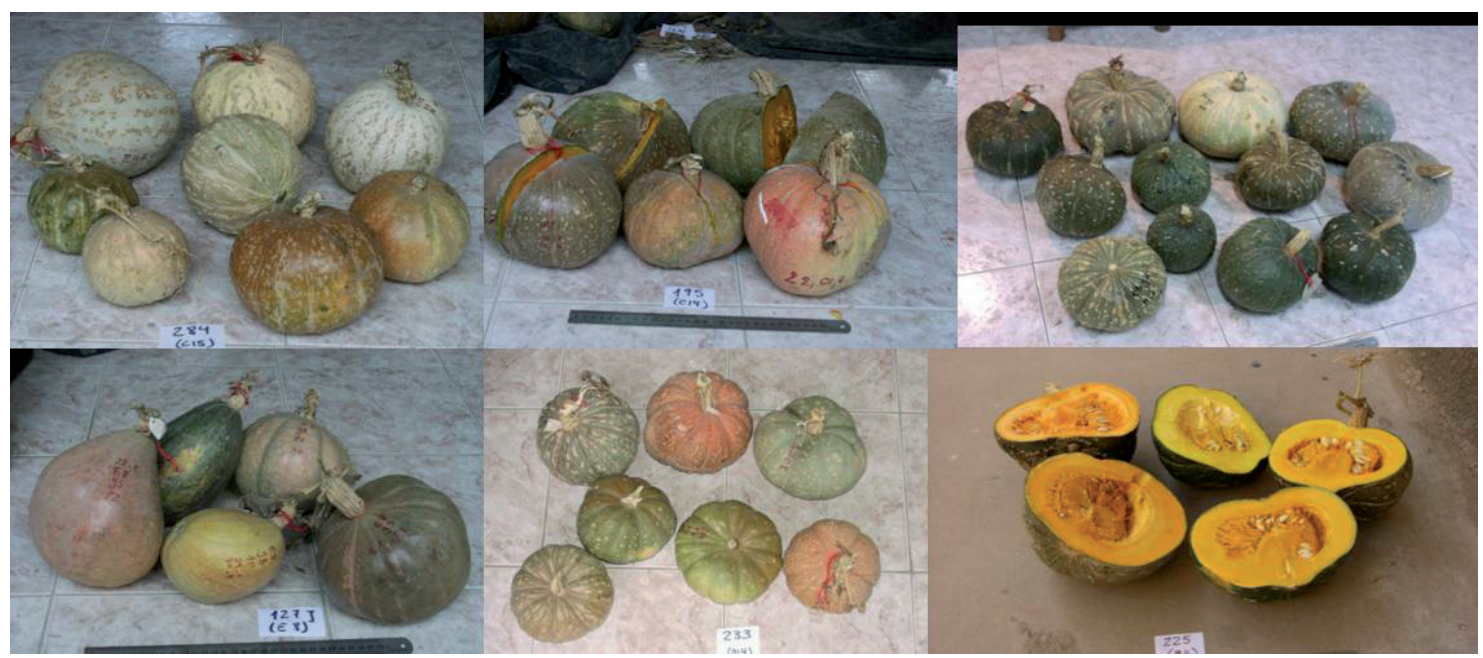

Figura 7. Frutos del grupo 3 (subgrupo "a") según el análisis de conglomerados. 
rondan los $2,8 \mathrm{~kg}$, semillas más grandes y pesadas que van del color crema al tostado. Presenta ciclos más cortos con 72 días a primera flor femenina (Figura 8).

Grupo 4: poblaciones con frutos de gran diversidad de formas: acorazonados, globosos, ovales y chatos. Plantas guiadoras, con zarcillos, ovarios globosos y en menor medida fusiformes. Pulpas que van del anaranjado intenso a medio; semillas color crema. El ciclo vegetativo es intermedio a largo con 66 días promedio a primera flor femenina. Los rendimientos fueron de un fruto por planta y $340 \mathrm{~g}$ de semilla por fruto. Abarca las poblaciones con mayor tamaño de fruto y calidad de pulpa. El subgrupo 4 "a" (Figura 9) desarrolla plantas más vigorosas, con frutos de gran tamaño de $3,7 \mathrm{~kg}$ promedio. El subgrupo "b" desarrolla plantas menos vigorosas con frutos de $3 \mathrm{~kg}$ en promedio (Figura 10).

El ordenamiento de las poblaciones a través del análisis de conglomerados fue similar al de los dos análisis de ordenamiento previos (ACP, AC), con algún desplazamiento de aquellas poblaciones constituidas por mezclas muy diversas de morfotipos como las entradas 161, 215, 76 y 143. El análisis permitió visualizar las relaciones entre poblaciones identificando su agrupamiento natural y en relación con los testigos. Discriminó las poblaciones del grupo 3, observado en los ACP y $\mathrm{AC}$, en dos grupos distintos, hecho que facilita la interpretación de los ordenamientos y el manejo de las poblaciones en el Banco de Germoplasma. Las

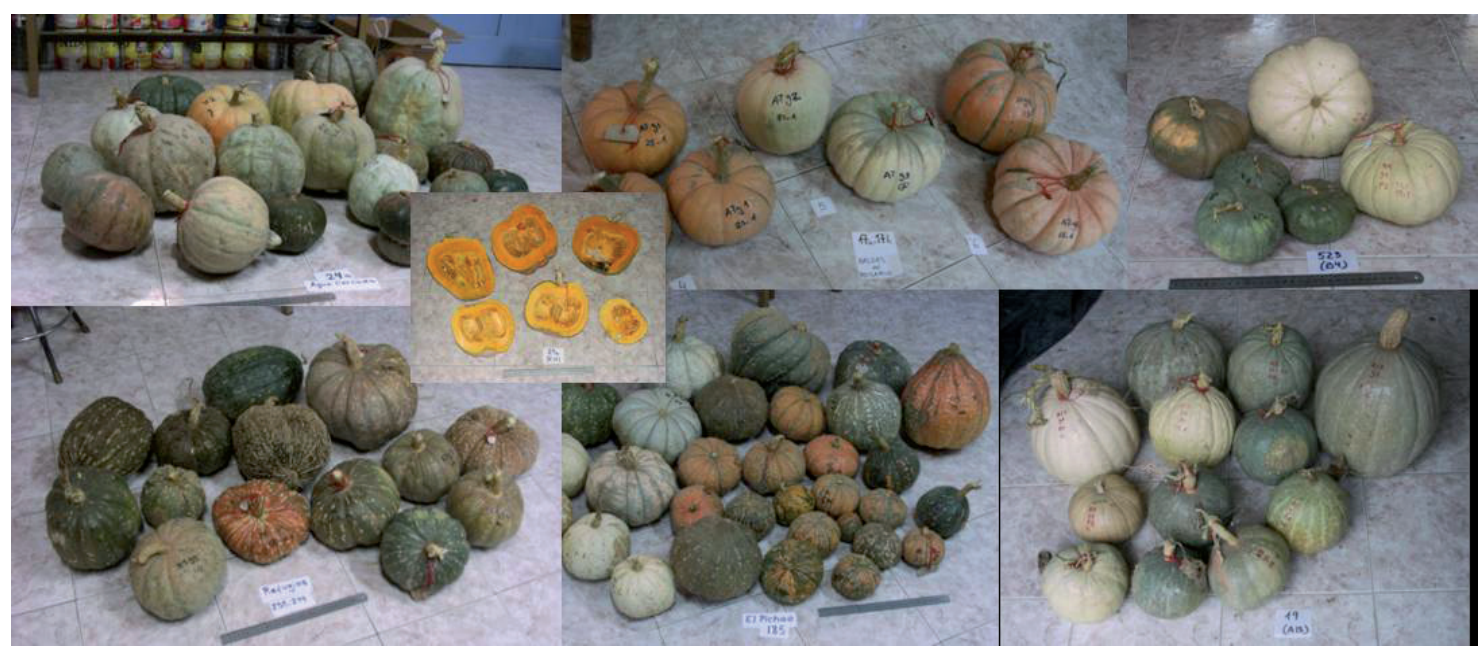

Figura 8. Frutos del grupo 3 (subgrupo "b") según el análisis de conglomerados.

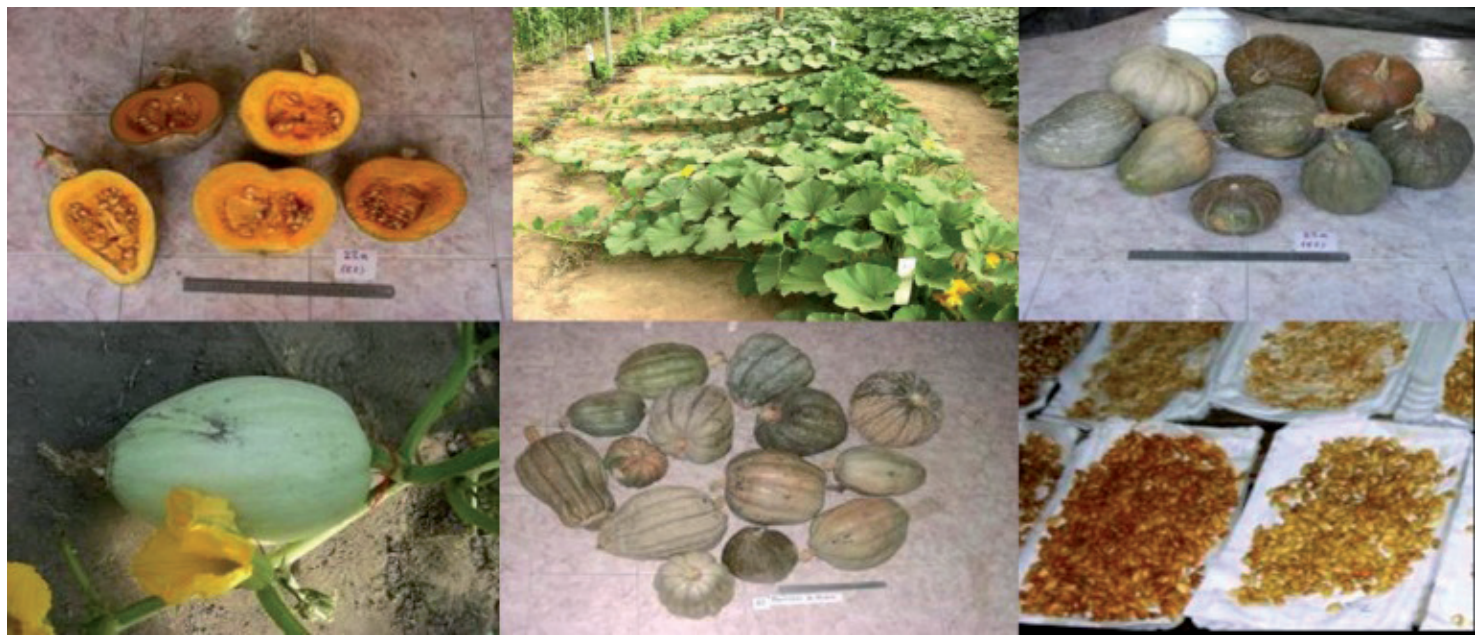

Figura 9. Frutos del grupo 4 (subgrupo "a") según el análisis de conglomerados. 


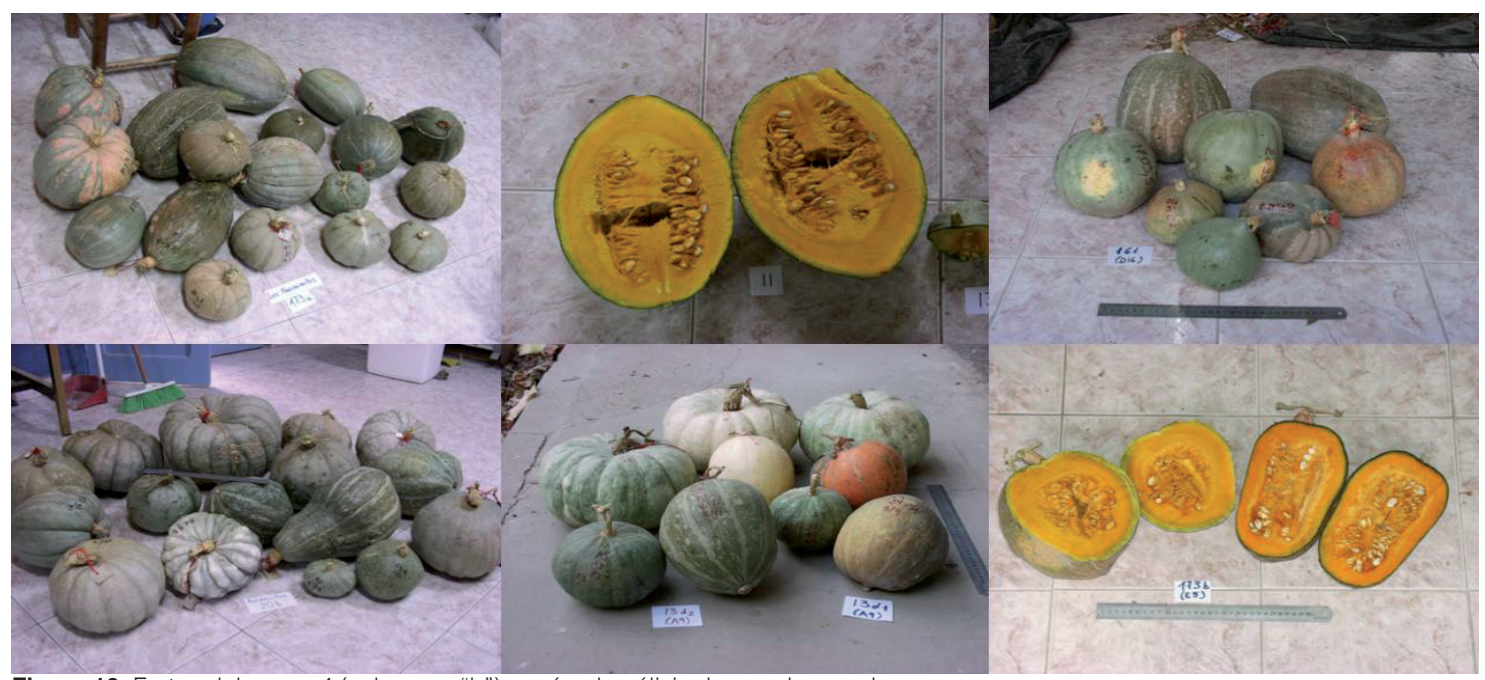

Figura 10. Frutos del grupo 4 (subgrupo "b") según el análisis de conglomerados.

distancias calculadas permiten inferir relaciones de parentesco entre poblaciones y recomendar parentales para la obtención de nuevos cultivares. El origen de las poblaciones no influyó en la ordenación obtenida.

\section{Obtención de semilla}

Por medio de la polinización dirigida dentro de cada población, se obtuvo semilla suficiente para asegurar su preservación en el tiempo. Se cumplió con las Normas de Procedimientos de Bancos de Germoplasma del INTA establecidas por Clausen (2004) que sugieren para Cucurbita sp. el resguardo de 1000 semillas por entrada. Actualmente las semillas se conservan en el mediano plazo en el Banco de Germoplasma de la EEA La Consulta INTA y a largo plazo en el Banco Base, EEA Castelar INTA. Se cumple así con la premisa de preservar estas poblaciones de la erosión genética y extinción. Los rendimientos promedio en semilla fueron de $1922 \mathrm{~g}$ por población a lo largo de 2 años de multiplicación, con un desvío estándar de $455 \mathrm{~g}$ y un coeficiente de variación del $24 \%$. La población 22 alcanzó los rindes más altos con $3099 \mathrm{~g}$, mientras que la 233 resultó la de menor producción con $1168 \mathrm{~g}$ de semillas.

\section{Poblaciones de interés agronómico}

Muchas de las poblaciones evaluadas manifestaron tener caracteres de interés para la industria, el mercado y el mejoramiento vegetal. La población "143" se destaca por su atractivo visual, con frutos grandes, turbaniformes, de colores anaranjados intensos y brillantes, corteza dura y larga conservación en poscosecha, cualidades de interés para su empleo como ornamental. Por otra parte, algunas plantas de esta población producen frutos chatos, redondos, de intenso color naranja, pesos que rondan los $2 \mathrm{~kg}$ y un espesor considerable de pulpa, pudiendo resultar novedosos para el consumidor por su calidad, tamaño adecuado para la comercialización individual y por su atractivo visual. La población "284" presenta frutos uniformes, de formas globosas, colores grisáceos y decorados con cicatrices corchosas en la corteza. El peso de los frutos es adecuado para su comercialización individual con una media de $1674 \mathrm{~g}$. Sus plantas son muy vigorosas con guías que rondan los $6 \mathrm{~m}$ de longitud y ciclos vegetativos largos que las hacen adecuadas para regiones de veranos extensos, libres de heladas, situación en la que rinden dos y más frutos por planta. La población "36" produce frutos grandes de color gris plomizo, con un peso promedio de $4100 \mathrm{~g}$, pulpas gruesas y de color anaranjado intenso, esta última variable correlacionada con abundancia en carotenos. Las características mencionadas resultan de utilidad para la industria del deshidratado. El ciclo vegetativo es corto adaptándose a regiones con veranos breves. La población "382" produce frutos de la variedad zapallito del tronco, con plantas vigorosas, sanas y de altos rendimientos. Las poblaciones "53", "244", "17", "13" y "195" presentan valores de tono (Hue) menores a $90^{\circ}$ y elevada intensidad o saturación (Croma) del color de la pulpa, factores que se correlacionan con altos niveles de beta y alfa carotenos, ambos pigmentos precursores de la vitamina 
A, y de luteína que actúa como antioxidante (Itle \& Kabelka, 2009). El color de pulpa es un carácter de moderada a alta heredabilidad $(0,81-0,93)$ (Itle \& Kabelka, 2009), por lo que estas mediciones de color permiten seleccionar indirectamente por calidad de fruto.

\section{CONCLUSIONES}

La evaluación morfo-agronómica permitió conocer las características más relevantes de 27 poblaciones criollas de $C$. maxima colectadas en los valles andinos de San Juan y el NOA. Los resultados demostraron que existe gran diversidad dentro de las poblaciones evaluadas y entre ellas, y que dentro de esa diversidad se encuentran poblaciones con características deseables para el mejoramiento. Las variables relacionadas con la forma y peso de fruto, grosor y color de la pulpa, y hábito de crecimiento fueron las de mayor utilidad para diferenciar poblaciones de C. maxima. Mediante las mediciones de color de pulpa se pudieron discriminar poblaciones por su calidad nutricional.

El trabajo permitió la incorporación de las poblaciones evaluadas a la red de bancos del INTA, preservándolas de la erosión genética. Por último, se generó información de utilidad para el manejo, estudio, conservación y aprovechamiento de las entradas tanto en los planes de mejoramiento de la especie como en los bancos de germoplasma.

\section{AGRADECIMIENTOS}

Los autores agradecen a Pedro Della Gaspera por su asesoramiento en el cultivo de zapallo y a Cecilia Bruno por su asistencia en estadística.

El presente trabajo fue financiado por los siguientes proyectos e instituciones: Proyecto de Investigación Científica y Tecnológica Orientado (PICT-O 2002 N08-12903) Recuperación, Evaluación y Aprovechamiento Social del Germoplasma "Criollo" de Hortalizas en Regiones Andinas. Agencia Nacional de Promoción Científica y Tecnológica (ANPCYT), Secretaría de Ciencia, Tecnología e Innovación Productiva (SECTYP), UNCuyo e INTA. Filogeografía e implementación de un sistema de monitoreo molecular de la identidad genética de cultivos andinos (INTA-AEBIO 2443 EPPR), 20062008).

Esta publicación es parte de la tesis doctoral en Ciencias Biológicas (PROBIOL) de Inés María Lorello, UNCuyo.

\section{BIBLIOGRAFÍA}

Instituto Nacional de Semillas INASE. Anexo ii-Descripción de cultivar de zapallo, zapallito y calabaza (Cucurbita spp.). <http://www.inase.gov.ar/index. php?option=com_content\&view=article $\& i d=101$ : desc riptorescultivares\&catid $=49 \&$ Itemid $=90>$ Consultada el 12/12/2015.

Asprelli, P.D.; I.M. Lorello, P.N. Occhiuto, L.S. Togno, M.A. Makuch, S.C. García Lampasona and I.E. Peralta, 2012. First collection of landrace vegetable crops cultivated in Valle Fértil, Argentina. Agriscientia 29:41-50.

Astorquizaga R, 2009. Cultivo de zapallo (Cucurbita sp.) en el Noroeste de Chubut. Agricultura 15:61-64.

Balkaya, A.; M. Özbakir and E. SaitKurtar, 2010. The phenotypic diversity and fruit characterization of winter squash (Cucurbita maxima) populations from the Black Sea Region of Turkey. African Journal of Biotechnology 9: 152-162

Balzarini, M.G.; L. Gonzalez, M. Tablada, F. Casanoves, J.A. Di Rienzo y C.W. Robledo, 2008. Manual del Usuario, Editorial Brujas, Córdoba, Argentina. 250p

Bih Achu, M.; E. Fokou, C. Tchiégang, M. Fotso and F. Mbiapo Tchouanguep, 2005. Nutritive value of some Cucurbitaceae oil seeds from different regions in $\mathrm{Ca}-$ meroon. African Journal of Biotechnology 4: 13291334.

Clausen, A.M., 2004. Normas de procedimiento para el funcionamiento de la Red de Bancos de Germoplasma del INTA. 40 p.

Della Gaspera, P. y R.A. Rodríguez, 2013. El género Cucurbita. En P. Della Gaspera (Eds.): Manual del cultivo del zapallo anquito (Cucurbita moschata Duch.). Ediciones Instituto Nacional de Tecnología Agropecuaria, pp. 9-24. I.S.B.N.: 978-987-521-465-1

Di Rienzo, J.A.; F. Casanoves, M.G. Balzarini, L. Gonzales, M. Tablada y C.W. Robledo, 2009. Infostat versión 2009. Grupo InfoStat, FCA, Universidad Nacional de Córdoba, Argentina.

Domínguez, O.; S.T. Peske, F.A. Villela y L. Baudet, 2000. Sistema Informal de Sementes: Causas, Conseqüências e Alternativas. Pelotas: UFPel. 270 p.

Ferriol, M.; B. Picó and F. Nuez, 2004. Morphological and Molecular Diversity of a Collection of Cucurbita maxima Landraces. J. Amer. Soc. Hort. Sci. 129: 60-69.

Gower, J.C., 1985. Measures of similarity, dissimilarity and distance.En Kotz S. and Jonhson N. Ed. Encyclopedia of Stastistical Science. Wiley, New York.Vol. 5.pp. 397- 405.

Guzmán, L.; G. Ávila y M. Céspedes, 2001. Catálogo de Recursos Genéticos Bolivianos de: Amaranthus, Capsicum, Cucurbitaceae, Lupinus y Phaseolus. Conservados en el Banco de Germoplasma del Centro de 
Investigaciones Fitoecogenéticas de Pairumani. Lista de Descriptores de Cucurbita. Fundación Simón I. Patiño. Cochabamba, Bolivia. 124 p.

Hurd, P.D. JR. and E.G. Linsley, 1964. The squash and gourd bees-genera Peponapis Robertson and Xenoglossa Smith-inhabiting America north of Mexico. Hilgardia 35: 373-477.

Hurd, P.D. JR. and E.G. Linsley, 1967. South American squash and gourd bees of the genus Peponapis. Annals of the Entomological Society of America 60: 647661.

Hurd, P.D. JR. and E.G. Linsley, 1970. A classification of the squash and gourd bees Peponapis and Xenoglossa. University of California Publications in Entomology 62: i-iv + 1-39.

Hurd, P.D. JR.; E.G. Linsley and T.W. Whitaker, 1971. Squash and gourd bees (Peponapis, Xenoglossa) and the origin of the cultivated Cucurbita. Evolution 25: 218-234.

Itle, R.A. and E.A. Kabelka, 2009. Correlation between $\mathrm{L}^{*} \mathrm{a}^{*} \mathrm{~b}^{*}$ color space values and carotenoid content in pumpkins and squash (Curcurbita spp.). Hort Science 44: 633-637.

León, J., 2000. Botánica de los Cultivos Tropicales. Tercera edición revisada y aumentada. Editorial Agroamérica del IICA. San José, Costa Rica. 522 p.

Lira Saade, R., 1996. Estudios Taxonómicos y Ecogeográficos de las Cucurbitaceae Latinoamericanas de Importancia Económica. En: Systematic and Ecogeographic Studies on Crop Genepools N 9. IPGRI, Rome, Italy. pp. 1-115

Lorello, I.M., 2012. Recolección, conservación y caracterización morfológica y molecular de poblaciones "criollas" de zapallo (Cucurbita maxima) colectadas en los valles andinos de la Argentina. Phd Dissertation Abstracts 98, PROBIOL, Universidad Nacional de Cuyo, Mendoza.

Lorello, I.M.; S.C. García Lampasona e I.E. Peralta, 2013. Caracterización de zapallos criollos (Cucurbita maxima Duch.), colectados en Valle Fértil, San Juan, y en el noroeste argentino. XXXVI Congreso Argentino de Horticultura ASAHO y II Congreso Internacional de Plásticos Agrícolas. Tucumán, p. 298.

Matus, I.M.; G. Gonzales and A. Del Poso, 1996. Evaluation of phenotypic variation in a Chilean collection of garlic (Allium sativum L.) clones using multivariate analysis. Plant Genet. Res. Newsl. 117: 31-36.

McGuire, R.G., 1992. Reporting of Objective Color Measurements. Hort Science 27: 1254-1255.

McKay, J.W., 1931. Chromosome studies in the Cucurbitaceae. Univ. Calif. Publ. Bot. 16: 339-50.

Montes R.C.; C.F.A. Vallejo y G.D. Baena, 2004. Diversidad genética de germoplasma colombiano de zapallo
(Cucurbita moschata Dúchesne Exp. Prior). Revista de la Universidad Nacional de Colombia. Acta Agronómica 53: 43-50.

Morales, M.A.; I. Baños, J.M. Egea-Sánchez, J. Gomariz, E. Sánchez, J.M.B. Egea, J. Costa y M.S. Catalá, 2007. Caracterización de variedades locales de Cucurbita moschata y Lagenaria sicerarea colectadas en la Región de Murcia. XI Congreso SECH. Albacete. Actas de Horticultura $n^{\circ}$ 48. pp. 332-335.

Peralta, I.E.; M. Makuch, S. García Lampasona, P.N. Occhiuto, P.D. Asprelli, I.M. Lorello y L. Togno, 2008. Catálogo de Poblaciones Criollas de Pimiento, Tomate y Zapallo colectadas en Valles Andinos de la Argentina. Ediciones Instituto Nacional de Tecnología Agropecuaria. Mendoza, Argentina. 128p.

Rahman, A.H.M.M.; M. Anisuzzaman, F. Ahmed, A.K.M. Rafiul Islam and A.T.M. Naderuzzaman, 2008. Study of Nutritive Value and Medicinal Uses of Cultivated Cucurbits. Journal of Applied Sciences Research 4: 555-558.

Seroczy ska A.; Korzeniewska A.; Sztangret-Wi niewska J.; Niemirowicz-Szczytt K. and M. Gajewski, 2006. Relationship between carotenoids content and flower or fruit flesh colour of winter squash (Cucurbita maxima Duch.). Folia Horticulturae. Ann. 18/1: 51-61.

Torres Filho, J.; G.H. De Sousa Nunes, J.J. Cavalcanti Vasconcelos, J.H. Da Costa Filho e G. Guimarães Costa, 2009. Caracterização Morfológica De Acessos De Meloeiro Coletados No Nordeste Brasileiro. Revista Caatinga 22: 174-181.

Tsivelikas, A.L.; O. Koutita, A. Anastasiadou, G.N. Skaracis, E. Traka-Mavronaand M. Koutsika-Sotiriou, 2009. Description and Analysis of Genetic Diversity among Squash Accessions. Brazilian Archives of Biology and Technology 52: 271-283.

Vavílov, N.I., 1931. The Problem of the Origin of the World's Agriculture in the Light of the Latest Investigations. Science at the Crossroads. International Congress of the History of Science and technology. London. http:// www.marxists.org/subject/science/essays/vavilov.htm Consultada el 2/05/ 2010.

Weeden, N.F., 1984. Isozyme studies indicate that the genus Cucurbita is an ancient tetraploid. Cucurbit Gen Coop. Rpt. 7: 84-85.

Weeden, N.F. and R.W. Robinson, 1990. Isozyme studies in Cucurbita. En: R.W. Robinson, C. Jeffrey, and D.M. Bates (eds.) Biology and Chemistry of Cucurbitaceae. Cornell University Press, Ithaca, NY. pp. 51-59.

Whitaker, T.W., 1933. Cytological and phylogenetic Studies in the Cucurbitaceae. Bot.Gaz. 94: 780-790

Whitaker, T.W. and G.N. Davis, 1962. Cucurbits. Cultivation and utilization. Leonard Hill Ltd. London \& Interscience Publishers Inc., New York. 250p. 